\title{
Transfer of either index finger extensor tendon to the extensor pollicis longus tendon
}

\author{
Bryce M Meads MBChB FRACSOrth, Earl R Bogoch MD FRCSC
}

\begin{abstract}
BM Meads, ER Bogoch. Transfer of either index finger extensor tendon to the extensor pollicis longus tendon. Can J Plast Surg 2004;12(1):31-34.
\end{abstract}

BACKGROUND: Extensor pollicis longus (EPL) tendon ruptures have been treated succesfully with the transfer of the extensor indicis proprius (EIP) tendon. Situations exist in which, due to intraoperative observations, another tendon transfer may be considered preferable to the standard EIP transfer method.

OBJECTIVES: To determine whether transfer of the extensor digitorum communis II (EDC II) tendon from the index finger to the EPL tendon, leaving the EIP tendon to the index finger intact, would serve as an equally efficient transfer and not adversely affect the function of the hand.

METHODS: Two patients who had the EDC II tendon transferred to the ruptured EPL tendon, and two patients who had the EIP tendon transferred, were retrospectively reviewed. In each transfer type, one patient had suffered an EPL tendon rupture after a Colles' fracture, and the other had rheumatoid arthritis. The rupture occurred on the non-dominant side in one patient in each transfer type. Each patient was examined and subjected to range of motion and power testing at least one year following surgery.

RESULTS: All four patients showed a minimal extension lag with the lift off test, but there was no noticeable difference in range of motion, pinch grip and hand grip strength between the transfer types. Both EDC II transfer patients demonstrated an $8^{\circ}$ to $15^{\circ}$ loss of thumb interphalangeal joint flexion compared with the unoperated side; EIP transfer patients demonstrated less than a $5^{\circ}$ loss. Three patients demonstrated a minor extension lag in the index finger and middle finger. Extension power of the thumb and index finger in all patients varied with wrist flexion and extension and ranged from $50 \%$ to $150 \%$ of the unoperated side.

CONCLUSIONS: These case reports suggest that either index finger tendon may be successfully transferred in EPL tendon ruptures.

Key Words: Extensor digitorum communis II (EDC II); Extensor indicis proprius (EIP); Extensor pollicis longus (EPL); Rupture; Tendon transfer

\section{Le transfert du tendon extenseur d'un index au tendon long extenseur du pouce}

\begin{abstract}
HISTORIQUE : Des ruptures du tendon long extenseur du pouce (TLEP) ont été traitées avec succès grâce au transfert du tendon extenseur de l'index (TEI). Il arrive qu'en raison d'observations intraopératoires, le transfert d'un autre tendon soit jugé préférable à la méthode standard de transfert du TEI.
\end{abstract}

OBJECTIFS : Déterminer si le transfert du tendon extenseur commun du doigt II (TECD II) de l'index au TLEP, en laissant le TEI de l'index intact, constituerait un transfert tout aussi efficace, sans nuire à la fonction de la main.

MÉTHODOLOGIE : Deux patients dont le TECD II a été transféré au TLEP rompu et deux patients dont le TEI a été transféré ont fait l'objet d'une analyse rétrospective. Dans chaque type de transfert, un patient avait souffert d'une rupture d'un TLEP après une fracture de Pouteau, et l'autre souffrait de polyarthrite rhumatoïde. La rupture s'était produite du côté non dominant chez un patient de chaque type de transfert. Chaque patient a été examiné et soumis à des tests d'amplitude du mouvement et de puissance au moins un an après l'opération.

RÉSULTATS : Les quatre patients ont affiché un léger décalage de l'extension au test de Gerber, mais on ne remarquait aucune différence notable de l'amplitude du mouvement, de prise en pince et de force de préhension entre les types de transfert. Les deux patients ayant subi un transfert du TECD II ont démontré une perte de $8^{\circ}$ à $15^{\circ}$ de la flexion de l'articulation interphalangique du pouce par rapport au côté non opéré. Les patients ayant subi un transfert du TEI affichaient une perte de moins de $5^{\circ}$. Trois patients ont affiché un léger décalage de l'extension de l'index et du majeur. La puissance d'extension du pouce et de l'index de tous les patients variait selon la flexion et l'extension du poignet et oscillait entre $50 \%$ et $150 \%$ du côté non opéré.

CONCLUSIONS : Ces rapports de cas indiquent que le tendon de l'un des index peut être transféré avec succès en cas de ruptures du TEI.
$\mathrm{E}^{\mathrm{xtensor}}$ pollicis longus (EPL) tendon ruptures have been Etreated succesfully with the transfer of the extensor indicis proprius (EIP) tendon (1-10), which is usually located ulnar to the tendon of the extensor digitorum communis II (EDC II) to the index finger. Considerable variability in the anatomy of the extensor tendons of the index finger has been described (11-14). Situations exist in which, due to intraoperative observations, the reliability of the standard EIP transfer method may be in question. These conditions include fraying strands, multiple smaller strands and uncertain identification of the two tendons.

We proposed that transferring the EDC II tendon from the index finger to the EPL tendon, leaving the EIP tendon intact, would serve as a satisfactory transfer where conditions favour this, and that the choice of EDC II tendon would not adversely affect the function of the hand. 


\section{METHODS}

Four patients who had tendon transfers for EPL tendon rupture between 1992 and 1995 at a large urban hospital were reviewed. In two patients, the EDC II tendon was transferred to the ruptured EPL tendon, and in two other patients, the EIP tendon was transferred. In each transfer type, one patient had suffered an EPL tendon rupture after Colles' fracture, and the other patient had rheumatoid arthritis. The ruptures were acute and occurred on the nondominant side in one patient in each transfer type.

The operative technique involved identifying the extensor tendons to the index finger at the wrist and dividing the chosen tendon through a small transverse incision at the index metacarpophalangeal (MCP) joint. Through the dorsal wrist incision, the tendon was secured to the distal EPL stump by a tendon weave with sufficient tension to elevate the thumb off the operating table.

The thumb was immobilized in extension in a thumb spica for a minimum of four weeks. Following the removal of the cast, physiotherapy consultation was obtained to teach the use of the transfer, improve the range of motion of the thumb and to subsequently strengthen it. The minimum time until assessment of these patients was one year after surgery. Each patient was also given a subjective questionnaire regarding pain and functional limitations after the transfer.

Active and passive range of motion were measured with a goniometer. A pinchmeter was used to measure lateral, tip, and tripod pinch strength. Grip strength was measured using a Jamar dynamometer (Asimow Engineering Co, USA). An extensiometer (Penny and Giles Transducers, United Kingdom) was used to measure the power of extension of the thumb and index finger with full flexion and extension of the fingers.

\section{CASE PRESENTATIONS}

\section{Patient 1}

A right hand dominant, 32-year-old man who suffered from rheumatoid arthritis of six years duration experienced spontaneous rupture of the right EPL tendon. The EIP tendon was found to consist of two narrow, separate bundles, neither of which appeared to be suitable for transfer. Due to duplication of the EIP tendon, it was elected to transfer the EDC II tendon from the index finger to the distal stump of the EPL tendon.

\section{Patient 2}

A right hand dominant, 59-year-old woman sustained a rupture of her left EPL tendon 10 weeks after suffering an undisplaced Colles' fracture. At surgery, the EIP tendon was noted to be composed of separate, small bundles. Consequently, the EDC II tendon was transferred from the index finger to the distal stump of the EPL tendon. This patient showed a $30 \%$ decrease of thumb extension power compared with the unoperated side when fingers were flexed, but a $30 \%$ increase compared with the unoperated side when fingers were extended.

\section{Patient 3}

A right hand dominant, 71-year-old man who suffered from rheumatoid arthritis of 22 years duration sustained a spontaneous rupture of the right EPL tendon. This tendon was reconstructed with transfer of the EIP tendon.

\section{Patient 4}

A right hand dominant, 60-year-old man sustained a rupture of the EPL tendon eight weeks after an undisplaced distal radius fracture of the left hand. An EIP tendon transfer was performed. The range of motion of the index finger was greater in the operated than in the unoperated hand following surgery (Table 1). Pinch strength was somewhat reduced (Figure 1).

At final follow-up, all patients reported a slight subjective loss of power in the thumb. They reported no restriction in their ability to perform activities of daily living. No patient reported a loss in the range of motion of the thumb of the operated hand compared with the unoperated side.

Outcome measures, including extension power of the thumb and middle finger, and comparisons of the active range of motion of the thumb, MCP extension and flexion of the index and middle finger, and grip strength of the operated side to the unoperated side are summarized in Table 1. Pinch strength, as measured by tip pinch strength, key pinch strength and tripod pinch strength, is shown in Figure 1.

\section{DISCUSSION}

Rupture of the EPL tendon occurs at the level of the wrist in rheumatoid arthritis and after fracture of the distal radius (9). Due to the attritional loss of tendon substance, primary repair of the tendon is usually not possible. Additional shortening of the proximal end may occur through myostatic contracture, particularly if the presentation is delayed.

To achieve restoration of EPL function, either tendon grafting or tendon transfer is indicated. Intercalated tendon grafting has been successfully used (15), but this procedure requires two tendon repair sites and has the difficulty of overcoming myostatic contracture for appropriate tensioning.

Tendon transfers are more commonly performed, using the EIP tendon, or occasionally another tendon such as extensor carpi radialis longus $(7,16)$, extensor digitorum brevus manus (16) or palmaris longus (7). The most widely used method is transfer of the EIP tendon to the distal stump of the EPL tendon $(1-4,6,9,10,17,18)$. This tendon is usually the more ulnar positioned of the two extensor tendons of the index finger.

Several anatomical variations of the extensor tendons have been reported (11-14). The EDC II index tendon was found to be the most constant single tendon, whereas supernumerary or bifurcated tendons of the EIP were found in $13 \%$ of cases $(12-14)$. The EIP tendon also demonstrated variability in its relationship to the EDC II index finger tendon, inserting either palmar or radial to it in 19\% of dissections (14).

The range of motion of the interphalangeal (IP) joint of the thumb in the two cases of EDC II tendon transfer showed a minor loss of flexion $\left(15^{\circ}\right.$ and $8^{\circ}$, respectively), independent of the position of the fingers. This was not considered to be a functional deficit by the patients. No such diminution of IP joint motion was demonstrated with the two cases of EIP tendon transfer, although a similar loss of IP joint flexion has previously been noted in EIP transfer $(9,10)$. In contrast, Germann et al (2) showed a loss of $14^{\circ}$ to $30^{\circ}$ of IP joint flexion compared with the unoperated side. Magnussen et al (18) considered that loss of thumb IP flexion gave rise to no functional problems.

A small loss of elevation of the thumb was found in both transfer types, with a lag of $1.0 \mathrm{~cm}$ to $2.4 \mathrm{~cm}$ in the four patients compared with the unoperated side. A similar or slightly greater loss of elevation of the thumb was noted by 
TABLE 1

Outcome measures at one year following tendon transfer

\begin{tabular}{|c|c|c|c|c|}
\hline Patient & 1 & 2 & 3 & 4 \\
\hline Tendon transferred & EDC II & EDC II & EIP & EIP \\
\hline \multicolumn{5}{|l|}{ Extension power of thumb $(\mathrm{kg})$} \\
\hline \multicolumn{5}{|l|}{ Independent extension (flexed fingers) } \\
\hline Operated hand & 2.3 & 1.4 & 1.8 & 2.1 \\
\hline Unoperated hand & 2.0 & 2.1 & 2.8 & 4.2 \\
\hline \multicolumn{5}{|c|}{ Dependent extension (extended fingers) } \\
\hline Operated hand & 3.0 & 1.8 & 1.5 & 1.1 \\
\hline Unoperated hand & 3.1 & 1.2 & 2.8 & 1.3 \\
\hline \multicolumn{5}{|l|}{ Extension power of index finger $(\mathrm{kg})$} \\
\hline \multicolumn{5}{|l|}{ Independent extension (flexed fingers) } \\
\hline Operated hand & 1.7 & 1.0 & 0.9 & 0.8 \\
\hline Unoperated hand & 1.7 & 1.1 & 0.9 & 1.1 \\
\hline \multicolumn{5}{|c|}{ Dependent extension (extended fingers) } \\
\hline Operated hand & 2.4 & 0.7 & 0.7 & 0.8 \\
\hline Unoperated hand & 2.2 & 1.4 & 0.9 & 0.9 \\
\hline \multicolumn{5}{|l|}{ Thumb } \\
\hline Active range of motion at IP joint ${ }^{*}$ & $-15^{\circ}$ & $-8^{\circ}$ & $<-5^{\circ}$ & $<-5^{\circ}$ \\
\hline Flexion to base of little finger* & 0 & 0 & 0 & 0 \\
\hline Opposition* & 0 & 0 & 0 & 0 \\
\hline Lift off test $(\mathrm{cm})^{*}$ & -1.1 & -1.0 & -1.0 & -2.4 \\
\hline \multicolumn{5}{|l|}{ Index finger MCP } \\
\hline Extension* & $-10^{\circ}$ & $-4^{\circ}$ & $-12^{\circ}$ & $+8^{\circ}$ \\
\hline Flexion* & 0 & 0 & $-17^{\circ}$ & $+10^{\circ}$ \\
\hline \multicolumn{5}{|l|}{ Middle finger MCP } \\
\hline Extension* & $-8^{\circ}$ & 0 & $-8^{\circ}$ & $-3^{\circ}$ \\
\hline Flexion* & 0 & 0 & $-28^{\circ}$ & $-6^{\circ}$ \\
\hline Grip strength ( $\%$ of unoperated side) & 100 & 96 & 80 & 88 \\
\hline
\end{tabular}

${ }^{*}$ Difference: Operated side less unoperated side. EDC I/ Extensor digitorum communis II; EIP Extensor indicis proprius; IP Interphalangeal joint; MCP Metacarpophalangeal joint

Noorda and Hage (4), with a mean loss of $2.1 \mathrm{~cm}$ to $3.0 \mathrm{~cm}$ in their series. Lemmen et al (17) reported a loss of thumb elevation expressed as an angle of deficiency, ranging from $10^{\circ}$ to $20^{\circ}$ in 20 EIP transfers. A loss of thumb extension was also found by De Smet et al (1) and Magnussen et al (18).

Harvesting of an index finger extensor tendon induced a minor MCP joint extension lag of $4^{\circ}$ to $12^{\circ}$ in the index finger in three of the four patients in this study. Noorda et al (5) reported a combined extension lag of the MCP, proximal IP and distal IP joints of the index finger of $5^{\circ}$ to $105^{\circ}$ in 24 of 34 patients after transfer of the EIP tendon. Similar studies reported an extension lag of the index MCP joint ranging from $10^{\circ}$ to $20^{\circ}$ in seven of 27 patients (8), from $4^{\circ}$ to $20^{\circ}$ in four of six patients (10), or a mean extension lag of $25^{\circ}$ in 13 patients (1). Several authors have suggested that extensor lag of the index finger following transfer is most likely the result of scarring induced around the extensor hood, rather than from the loss of extension power after EIP transfer $(5,8,19,20)$. In a recent study, Low et al (3) suggest that loss of thumb extension and flexion and loss of index extension may be limited in EIP transfer by using an alternate position for immobilization, whereby tensioning is done with the wrist in neutral position and the thumb in full extension. In the current study, the middle finger showed either no extensor lag, or a minimal extensor lag of $3^{\circ}$ to $8^{\circ}$.

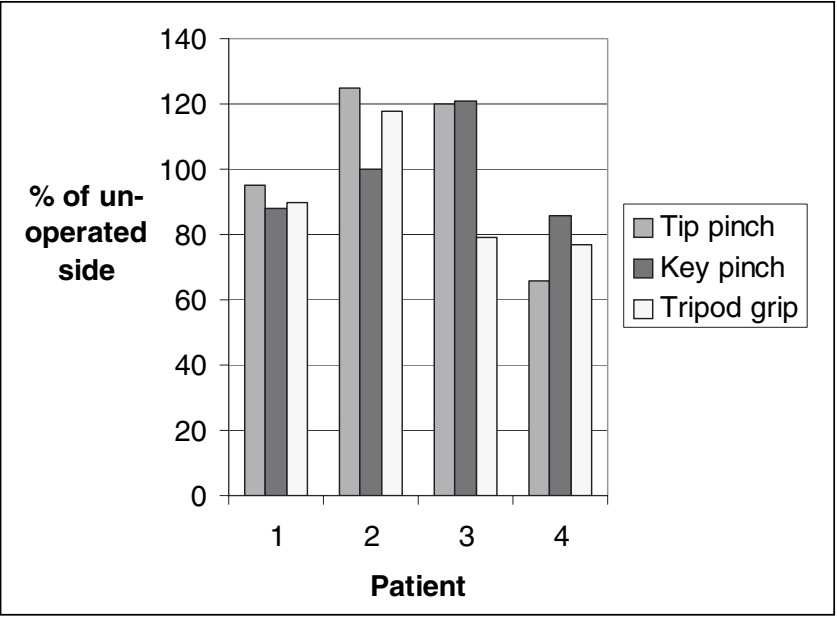

Figure 1) Tip pinch strength, key pinch strength and tripod pinch strength, expressed as a percentage of the unoperated side. Patient 1 (extensor digitorum communis II [EDC II] transfer) and patient 3 (extensor indicis proprius [EIP] transfer) underwent operations on the dominant hand. Patient 2 (EDC II) and patient 4 (EIP) underwent operations on the nondominant hand

Pinch strength losses of $8 \%(4), 10 \%(6), 12 \%$ (10), $13 \%$ (1), and as high as 20\% (2) have been reported in EIP transfer patients, whereas Lemmen et al (17) reported a loss of only $2 \%$. The cases reviewed here show some variability in different pinch strength measurements, with one patient in each transfer type showing greater values in the operated hand when compared to the unoperated side. This does not appear to be related to hand dominance, but may possibly relate to rheumatoid disease activity in both the operated and unoperated hands. Three of the four patients showed grip strength that was similar to the unoperated side.

The power of extension of the operated thumb compared to the unoperated thumb, described as a percentage of the unoperated thumb, ranged from $67 \%$ to $150 \%$ in the EDC II transfer patients and from $50 \%$ to $85 \%$ in the EIP transfer patients.

Noorda et al (5) reported a loss of extension power of the index finger of $36 \%$ in dependent extension (with fingers extended) and $50 \%$ in independent extension (with fingers flexed) after EIP transfer. In one case described here (patient 2, EDC II transfer), there was a 50\% loss of dependent extension power and a minimal change in independent extension power of the index finger. There were no other observations of significant loss of extension power in the index finger. It is well established that the EIP tendon is anatomically separate and relatively functionally independent. The muscle belly of the EDC II separates at a point two-thirds along its length, as described by Lieber et al (21). Presumably, this proximal anatomical separation allows the EDC II tendon some independence of function, similar to the EIP tendon.

This review of four cases of EPL reconstruction, matched for etiology, demonstrates no major problem or advantage after transfer of the EDC II tendon, compared with the standard method of transfer of the EIP tendon. Based upon information in the literature and our experience with these and other cases, we are prepared to transfer either EDC II or EIP tendon, depending on the condition of the tendons. Where the EIP 
tendon is supernumerary or small, or where the identity of the tendon is in doubt, transfer of the EDC II tendon appears to be a satisfactory option. A review of a larger number of cases is required to confirm this experience.

ACKNOWLEDGEMENTS: The authors wish to thank Dr Krishan Rajaratnam, who assisted with patient review, Dagmar Gross who assisted in the preparation of the manuscript, and Dr David Hastings, who raised the clinical issue addressed above.

\section{REFERENCES}

1. De Smet L, Van Loon J, Fabry G. Extensor indicis proprius to extensor pollicis longus transfer: Results and complications. Acta Orthop Belgica 1997;63:178-81.

2. Germann G, Wagner H, Blome-Eberwein S, Karle B, Wittemann M. Early dynamic motion verus postoperative immobilization in patients with extensor indicis proprius transfer to restore thumb extension: A prospective randomized study. J Hand Surg [Am] 2001;26:1111-5.

3. Low CK, Pereira BP, Chao VT. Optimum tensioning position for extensor indicis to extensor pollicis longus transfer. Clin Orthop 2001;388:225-32.

4. Noorda RJ, Hage JJ. Extensor indicis proprius transfer for loss of extensor pollicis longus function. Arch Orthop Trauma Surg 1994;113:327-9.

5. Noorda RJ, Hage JJ, de Groot PJ, Bloem JJ. Index finger extension and strength after extensor indicis proprius transfer. J Hand Surg [Am] 1994;19:844-9.

6. Orljanski W, Gaterrer R, Schurz M, Schabus R. Rupture of the extensor pollicis longus tendon after wrist trauma. Acta Chir Plast 2002;44:129-31.

7. Moore JR, Weiland AJ, Valdata L. Tendon ruptures in the rheumatoid hand: Analysis of treatment and functional results in 60 patients. J Hand Surg [Am] 1987;12:9-14.

8. Moore JR, Weiland AJ, Valdata L. Independent index extension after extensor indicis proprius transfer. J Hand Surg [Am] 1987;12:232-6.

9. Schneider LH, Rosenstein RG. Restoration of extensor pollicis longus function by tendon transfer. Plast Reconstr Surg 1983;71:533-7.

10. Thoma A, Quttainah A. Extensor indicis proprius tendon transfer for extensor pollicis longus rupture. Can J Plast Surg 2001;9:139-42.

11. Beatty JD, Remedios D, McCullough CJ. An accessory extensor tendon of the thumb as a cause of dorsal wrist pain. J Hand Surg [Br] 2000;25:110-11.

12. Gonzalez MH, Weinzweig N, Kay T, Grindel S. Anatomy of the extensor tendons to the index finger. J Hand Surg [Am] 1996;21:988-91.

13. Komiyama M, Nwe TM, Toyota N, Shimada Y. Variations of the extensor indicis muscle and tendon. J Hand Surg [Br] 1999;24:575-8.

14. von Schroeder HP, Botte MJ. Anatomy of the extensor tendons of the fingers: Variations and multiplicity. J Hand Surg [Am] 1995;20:27-34.

15. Hamlin C, Littler JW. Restoration of the extensor pollicis longus tendon by an intercalated graft. J Bone Joint Surg Am 1977;59:412-4.

16. Patel MR, Bassini L, Moradia V. Extensor digitorum brevis manus tendon transfer to restore function of the extensor pollicis longus. J Hand Surg [Am] 1996;21:85-8.

17. Lemmen MH, Schreuders TA, Stam HJ, Hovius SE. Evaluation of restoration of extensor pollicis function by transfer of the extensor indicis. J Hand Surg [Br] 1999;24:46-9.

18. Magnussen PA, Harvey FJ, Tonkin MA. Extensor indicis proprius transfer for rupture of the extensor pollicis longus tendon. J Bone Joint Surg Br 1990;72:881-3.

19. Browne EZ Jr, Teague MA, Snyder CC. Prevention of extensor lag after indicis proprius tendon transfer. J Hand Surg 1979;4:168-72.

20. Kitano K, Tada K, Shibata T, Yoshida T. Independent index extension after indicis proprius transfer: Excision of juncturae tendinum. J Hand Surg [Am] 1996;21:992-6.

21. Lieber RL, Jacobson MD, Fazeli BM, Abrams RA, Botte MJ. Architecture of selected muscles of the arm and forearm: Anatomy and implications for tendon transfer. J Hand Surg [Am] 1992;17:787-98. 